\title{
L'(ab)ús del populisme de dretes del passat a Itàlia i els Països Baixos*
}

\author{
Stefan Couperus \\ UNIVERSITY OF GRONINGEN \\ s.couperusirug.nl
}

\section{Pier Domenico Tortola}

UNIVERSITY OF GRONINGEN

p.d.tortolaßrug.nt

Rebut: 28/02/2019

Acceptat: 28/09/2019

\section{RESUM}

L'anàlisi històrica s'utilitza cada vegada més com una eina en l'estudi del populisme actual a Europa. El passat sovint s'explora com una font d'analogies per a examinar el populisme del present i altres vegades en busca de mecanismes causals per a explicar l'onada populista actual. En aquest article ens centrem en un tercer tipus de vincle entre el populisme i el passat, és a dir, les formes en què els moviments i líders populistes usen i abusen de la història i la memòria històrica en la recerca del suport popular. Aquesta perspectiva sobre el nexe populisme-història pot proporcionar una visió profunda de la composició ideològica d'aquests moviments i els votants d'aquests, així com de les dinàmiques i estratègies discursives emprades. Centrant-se en el populisme de dretes contemporani i el seu enfocament del passat obscur dels països europeus, el document elabora una anàlisi exploratòria que planteja tres formes en què els populistes usen i abusen del passat: (a) la reavaluació positiva de la història obscura, (b) el recurs de la història falsa, (c) l'evocació i negació posterior dels vincles amb el passat obscur. Quan els examinem, utilitzem exemples extrets dels casos d'Itàlia i els Països Baixos per a verificar la plausibilitat de les nostres categories en diferents casos nacionals.

Paraules clau: populisme, història, Itàlia, Holanda.

\section{ABSTRACT. Right Wing Populism's (Ab)use of the Past in Italy and the Netherlands}

Historical analysis is increasingly used as a tool in the study of present-day populism in Europe. The past is often explored as a source of analogies through which to examine today's populism, and at other times in search of causal mechanisms to explain the current populist wave. In this paper we focus on a third kind of link between populism and the past, namely the ways populist movements and leaders use and abuse history and historical memory in their quest for mass support. This angle on the populism/history nexus can yield deep insight into the ideological make-up of these movements and their voters, and populism's discursive dynamics and strategies. Focusing on contemporary right-wing populism and its approach to the dark past of European countries, the paper conducts an exploratory analysis that posits three ways in which the past is (ab)used by populists: (a) the positive reassessment of dark history; (b) the recourse to fake history; (c) the evocation and subsequent denial of links with the dark past. In examining each, we use examples taken from the cases of Italy and The Netherlands to check the plausibility of our categories across different national cases.

Keywords: populism, history, Italy, the Netherlands.

\footnotetext{
*Article traduït de l'anglès. El text original està publicat a Debats. Journal on Culture, Power and Society. Annual Review 4.
} 


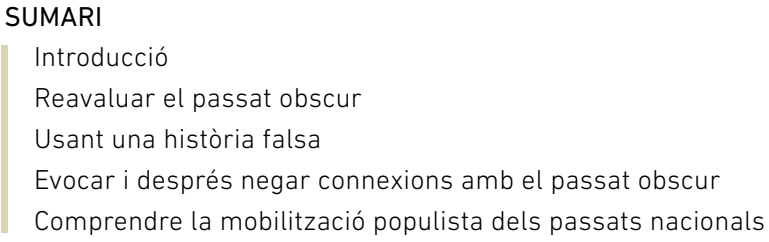

Autor per a correspondència / Corresponding author: Stefan Couperus, Faculty of Arts. European Politics and Society. Oude Kijk in't Jatstraat, 26. 9712 EK Groningen (Holanda).

Citació suggerida / Suggested citation: Couperus, S. i Tortola, P. D. (2019) L'(ab)ús del populisme de dretes del passat a Itàlia i els Països Baixos. Debats. Revista de cultura, poder i societat, 133(1), 11-25. DOI: http://doi.org/10.28939/iam.debats.133-2.2

\section{INTRODUCCIÓ}

El populisme - en particular en la versió de dretesés un dels desenvolupaments contemporanis més interessants i, possiblement, un dels més preocupants en la política de les democràcies europees i d'altres democràcies occidentals. L'auge del populisme es reflecteix en el gran augment d'estudis que n'examinen els orígens, les característiques, les trajectòries i els efectes en els diversos contextos nacionals (Canovan, 1981, 2005; Taggart, 2000; Mény i Surel, 2002; Mudde, 2007; Albertazzi i McDonnell, 2008; Wodak, 2015; Moffitt, 2016; Mudde i Rovira Kaltwasser, 2017; Müller, 2017; Eatwell i Goodwin, 2018).

Una xicoteta però creixent part del treball sobre el populisme de dretes d'Europa analitza les connexions d'aquest últim amb la història i, en general, amb el passat. Per exemple, sovint es compara entre el populisme contemporani i una sèrie d'experiències històriques, sobretot el feixisme d'entreguerres, per a identificar analogies i diferències en la naturalesa i el context polític més ampli que condueix a qualsevol dels fenòmens (McDougall, 2016; Eatwell, 2017; Finchelstein, 2017, 2018). Altres acadèmics examinen la història genealògicament tractant de rastrejar els vincles causals entre esdeveniments passats i conjuntures crítiques, així com l'aparició i l'èxit dels moviments populistes d'avui dia, i operant per mitjà de mecanismes institu- cionals i culturals o ideològics (Taggart, 2000; Fieschi, 2004; Mammone, 2009; Caramani i Manucci, 2019).

Una tercera manera en què el populisme de dretes i el passat poden vincular-se és mirant com els populistes usen la història en el seu idioma, les referències i els símbols com una manera de guanyar i consolidar el suport popular. Un aspecte que s'ha analitzat menys sistemàticament del nexe populisme-història és l'ús (i abús) del passat que n'han fet els populistes. Això no només fa llum a la composició ideològica i cultural d'aquests moviments polítics sinó que també ens diu molt sobre els qui els voten.

En termes generals, el passat políticament explotable es pot dividir en dues categories: el passat bo o noble i el passat roí o obscur. El primer comprén tots els esdeveniments, etapes històriques o personatges individuals que es veuen des d'un punt de vista principalment positiu dins del corrent cultural principal d'un país i que ajuden a articular l'autoimatge d'una nació i un imaginari nacional. Les històries embellides d'independència nacional, l'alliberament o la unificació, la celebració d'herois nacionals, les victòries de guerra i fets semblants pertanyen al passat noble. El passat obscur, per contra, inclou parts de la història (nacional) que comunament es veuen de manera negativa i com motius de vergonya per a un país. El 
feixisme, la col·laboració amb aquest i la guerra, així com les atrocitats colonials i imperials, ocupen un lloc central en el passat obscur d'Europa. No obstant això, depenent dels països en qüestió, hi ha altres episodis i etapes (per exemple, l'antisemitisme, el racisme, el genocidi, la guerra civil, la dictadura, etc.) que poden tenir el mateix pes.

Si bé el populisme de dreta (ab)usa d'ambdós passats, sostenim que val la pena examinar-ne el vincle amb el passat obscur. La naturalesa, en gran part indiscutible (almenys a escala nacional), del passat noble presenta dos resultats. El primer és que els populistes han de competir amb altres partits en l'explotació de la història amb una finalitat política. La segona és que, generalment, aquesta explotació és com una carrera d'apropiació, on els partits i moviments (inclosos els populistes) intenten fer-se passar pels hereus verdaders d'una determinada etapa històrica, figura, etc. ${ }^{1}$ El passat obscur és un joc completament diferent en què el populisme de dretes juga principalment sol. No obstant això, l'encantament del populisme amb el passat obscur planteja diversos desafiaments per a usar-lo amb una finalitat política. Per tant, observar la manera en què els populistes aborden aquests desafiaments no només ajuda a traçar els contorns de la seua perspectiva ideològica, sinó també a comprendre millor les eines discursives i retòriques dels recursos i de la manipulació que aquests moviments fan servir en la seua recerca del suport polític convencional.

Aquest article analitza tres formes en què un sector del populisme de dreta utilitza i abusa del passat obscur: (a) la reavaluació positiva de la història obscura, (b) el recurs de la història falsa, (c) l'evocació i negació posterior de les connexions amb el passat obscur. L'objectiu no és tant provar una tipologia exhaustiva sinó, més aviat (i més modestament), començar a

1 Considereu, per exemple, els intents repetits de l'italià Silvio Berlusconi, en molts sentits pare fundador del populisme de dreta contemporani a Europa, d'adquirir legitimitat política i respectabilitat, en retractar-se a si mateix i al seu partit, Forza Italia, com a portadors del llegat d'Alcide De Gasperi, fundador del partit demòcrata cristià italià i de la república del país posterior a la Segona Guerra Mundial (La Repubblica, 2003). posar una mica d'ordre en aquest tema i obrir el camí cap a estudis més sistemàtics en el futur. Aquesta anàlisi exploratòria utilitzarà els casos d'Itàlia i els Països Baixos per a il·lustrar les formes en què els populistes de dreta fan servir el passat obscur. En termes generals, aquesta selecció de casos està en línia amb el disseny d'investigació comparativa més diferent. Tot i que Itàlia i els Països Baixos són bastant diferents en termes d'història i cultura política, imaginaris nacionals i mobilització de la memòria històrica col-lectiva, ambdós països han vist el sorgiment de trops històrics contaminats, metàfores i referències en el discurs populista de dreta, com explicarem a continuació. En triar dos contextos polítics i culturals diferents dins dels quals els populistes de dreta han empleat estratègies discursives, retòriques i narratives semblants, esperem mostrar la plausibilitat de la nostra classificació preliminar de casos.

En les tres seccions següents de l'article exposem els tres modes d'utilització populista d'(ab)ús del passat mencionats anteriorment. Per a cadascun, presentem primer una descripció general, que després il·lustrem amb els casos d'Itàlia i els Països Baixos. En la cinquena i última secció, concloem amb una recapitulació del nostre argument i una reflexió sobre les implicacions de les nostres troballes per al treball futur sobre el tema del populisme i el passat.

\section{REAVALUAR EL PASSAT OBSCUR}

La manera més directa en què els populistes de dreta usen i manipulen la història és simplement observant el passat obscur des d'un punt de vista positiu. Això es fa, principalment, per mitjà de tres estratègies discursives parcialment superposades. La primera consisteix simplement a reinterpretar esdeveniments històrics, conjuntures o personatges controvertits perquè la imatge d'aquest siga més positiva i destacar-ne així els aspectes, els angles i els matisos més favorables. La segona estratègia és canviar i mantenir l'enfocament narratiu en alguns aspectes (inevitablement) positius d'una fase o experiència històrica negativa general. I la tercera consisteix a minimitzar la grave- 
tat o la responsabilitat nacional d'aquests fragments del passat obscur que són més difícils de minimitzar i presentar-los com errors, com treball de traïdors o com mesures preses sota coacció, etc.

En conjunt, aquestes tres maneres de reavaluar la història equivalen a un esforç ambiciós per part dels populistes per tornar a considerar nobles els fragments del passat obscur amb un doble objectiu: d'una banda, els populistes pretenen mobilitzar i encoratjar una certa part de l'electorat en l'extrema dreta de l'espectre polític (especialment els indecisos). De l'altra, i potser amb una ambició encara més gran, els populistes volen empentar el passat obscur al corrent cultural principal per poder atraure parts més moderades de l'electorat i que aquestes consideren la dreta una opció segura.

A Itàlia, la reavaluació del passat obscur fa referència, principalment, a l'època feixista. Tot i que l'extrema esquerra de l'espectre polític també fa servir aquesta reavaluació, especialment quan els partits d'esquerra es desplacen al centre (Mammone, 2006; La Stampa, 2018; Curridori, 2018), com era d'esperar el revisionisme d'Il ventennio (els vint anys de govern feixista) és més comú entre els partits de dreta. Aquests intents es presenten generalment com variacions en el tema comú «Mussolini també va fer coses bones» per embellir els èxits de la dictadura i així rehabilitar el passat feixista del país. Aquest extracte de Michaela Biancofiore (Ruccia, 2013), membre destacat de Força Itàlia, expressa bé aquest tipus de revisionisme:

Mussolini va fer moltes coses positives, especialment en l'àrea d'infraestructures i en la reactivació d'Itàlia. (...) Després, va portar el país a la guerra del costat de Hitler i això va ser un error. Però prenguem Bolzano (...) [quan] el feixisme va arribar ací, encara hi havia clavegueres a l'aire lliure (...) Mussolini va construir xarxes de clavegueres a tot Itàlia i no sols a l'Alto Adige. Mussolini va construir les autopistes. A Bolzano, tota l'àrea on ara es troba l'hospital, aquest vast tros de terra no existiria avui (...) perquè en aquell temps hi havia un mareny, que [el govern feixista] va drenar exactament com va fer amb les llacunes pontines (...) on van crear ocupació per a molts llauradors del Vèneto, que després es van establir allí. (...) Aquestes coses no es poden oblidar. (...) És cert que [Mussolini] va ser un dictador, però els dictadors de vegades deixen grans obres. (...) Com tots els grans homes, i Mussolini va ser un gran home de la història (...), no va ser tant ell, sinó el seu cercle íntim (...) qui va perpetrar la violència en nom seu.

La citació anterior conté molts dels trops d'aquest tipus de reinterpretació, inclosa la noció que Benito Mussolini va ser víctima del seu seguici. Roberta Lombardi, una de les líders del Moviment Cinc Estrelles, va proposar una descripció molt semblant del «bon feixisme» en un blog controvertit sobre el tema (Sofia, 2013): «abans que es degenerara, [el feixisme] tenia un sentit nacional de comunitat agafat completament del socialisme i un gran respecte per l'Estat i per la família». Ací no resulta estrany que l'extrema dreta de Matteo Salvini, Lliga Nord, haja presentat les reavaluacions més extremes. En una entrevista, Mario Borghezio, un provocador incendiari del partit (Davi, 2015), va dur a terme una reavaluació històrica més enllà de les fronteres d'Itàlia per a proposar una reinterpretació positiva del règim nazi:

Si hi ha un personatge d'aquell període que m'agrada molt és Walther Darré (que era el que avui anomenaríem ministre de Medi Ambient). Va ser ell qui va introduir l'ambientalisme en la política. (...) Sense mencionar [els avanços nazis en] altres àrees, com la investigació científica i el càncer. (...) Encara no hi ha hagut una escola historiogràfica capaç d'interpretar millor aquell període. (...) Per descomptat, la pàgina l'Holocaust continua sent una taca en la història.

A diferència de les associacions d'Itàlia amb els moviments o actors feixistes, tals referències encara són un tabú en el panorama polític holandés avui dia, a excepció d'una minoria marginal neonazi. Les referències al moviment nacionalsocialista holandés d'entreguerres s'utilitzen amb poca freqüència -encara que de manera hiperbòlica-, per l'esquerra i la dreta per igual, per a acusar els opositors (polítics) de (alta) traïció, feixisme o racisme. Així doncs, no 
és l'autoritarisme o el feixisme d'entreguerres el que modela les estratègies discursives del populista de dretes sobre el passat obscur. Més aviat, se centren en el passat colonial que s'ha utilitzat (malament) per a blanquejar una de les pàgines més negres de la història holandesa. El discurs públic i intel-lectual sobre la història de l'esclavitud i de l'esclavisme, l'imperialisme i la violència colonial (particularment la guerra a Indonèsia) ha acceptat cada vegada més la culpa col-lectiva de la nació. A diferència d'aquesta posició, els líders populistes de dreta o nativistes tendeixen a desafiar aquesta interpretació. És preocupant que els polítics centristes també hagen començat a aprofitar-se d'aquest revisionisme, fet que confirma l'observació de Ruth Wodak (2015) que les topoi (convencions retòriques) populistes de dreta s'han convertit en el corrent principal en el discurs polític.

Des que el primer ministre demòcrata cristià, Jan Peter Balkenende, va proposar infamement la invocació de «l'actitud mercantil de la Companyia Holandesa de les Índies Orientals» en 2006, que va ser molt criticada pels mitjans i el parlament, les referències al passat colonial en el discurs polític han estat contrites. En el context de la divulgació de noves revelacions històriques de mal comportament $i$ atrocitats imperials holandeses, hi ha un ampli consens acadèmic i públic sobre les males accions holandeses a l'estranger.

Recentment, estàtues de famosos però infames capitans i comerciants de la Companyia Holandesa de les Índies Orientals, així com carrers, places i edificis que porten els seus noms, van formar part de la discussió global emergent sobre la descolonització de la societat i els espais públics. En aquest context, els populistes i nativistes de dreta van començar a desplegar una contranarrativa de disculpa sobre un passat colonial noble o fins i tot nostàlgic.

Quan un bust d'un traficant d'esclaus aristocràtic del segle xvir va ser retirat d'un edifici públic, el dretà nacional populista Martin Bosma (membre del Partit per la Llibertat, de Geert Wilders, PVV) ho va veure com a «part d'una interminable iconoclàstia políticament correcta que amenaça la nostra història i la nostra cultura» (Elsevier, 2018). De la mateixa manera, Thierry Baudet, el líder del partit conservador Fòrum per la Democràcia (FvD), argumentava nostàlgicament que «hi va haver un temps en què el món sencer ens pertanyia», després de tot això va agregar que no hauria d'abandonar-se l'«últim tros de grandesa», en referència als territoris holandesos d'ultramar a les Antilles (Trouw, 2017). Altres vegades, Baudet $\mathrm{i}$ el seu grup van emprar reproduccions de (pretesos) vaixells de la Companyia Neerlandesa de les Índies Orientals i en un altre moment va fer una entrevista en una rèplica d'un dels navilis perquè «va ser una empresa esplèndida i una aventura com cap altra» (Forum, 2017). Es poden mencionar molts exemples semblants, incloses les declaracions que van fer els populistes de dreta locals, que desafien la narrativa de la culpa colonial i reiteren les celebracions a l'estil del segle xix d'un passat imperial gloriós modelat per les esplèndides virtuts dels holandesos.

Com a tal, els revisionistes han qüestionat la reavaluació gradual del passat colonial holandés perquè són còmplices en el tràfic d'esclaus, l'esclavitud, la violència genocida i l'opressió dels pobles. Aquest revisionisme té tres línies: (1) disculpa («del colonialisme van sorgir coses bones»), (2) nativisme (alguns crítics ho veuen com un intent de «blanquejar un passat obscur»), (3) nostàlgia («hauríem d'estar orgullosos dels nostres èxits colonials»). Aquestes respostes estan representades en gran part per populistes de dreta en el discurs polític i públic holandés. Les virtuts i els ideals nacionals es projecten en un passat mític i el costat obscur de la història es minimitza o simplement s'ignora.

\section{USANT UNA HISTÒRIA FALSA}

A més de reavaluar les etapes històriques, els fets i els personatges, els populistes poden inventar la història i els esdeveniments, embellir altres casos, usar dades incorrectes, invocar imatges imaginàries del passat, etc. S'involucren en allò que Furedi (2018: 87) ha denominat la manipulació de la memòria «per fabricar una edat d'or gloriosa i un passat nacional heroic». Anomenem aquestes estratègies «història falsa» per 
ressaltar-ne la connexió amb les nocions ara populars de notícies falses o afirmacions de postveritat, que els populistes empren de manera particularment audaç per a mobilitzar el seu electorat. La invenció de fets i dades històriques és una versió una mica més sofisticada del mateix joc.

Aquest segon tipus d'abús de la història és semblant i de vegades se superposa al primer. En certa manera, reavaluar determinats esdeveniments històrics, fases $o$ personatges és un exercici de falsificació de la història. L'historiador Andrea Mammone (2006) captura bastant bé la superposició entre aquests dos tipus de distorsió amb la noció d'història artificial. En les narracions i interpretacions històriques en gran part indiscutibles del passat, la història falsa agrega quelcom de nou a les interpretacions col-loquials del passat obscur. Presenta una contraevidència falsa i inexacta per mitigar un passat obscur donat. Posteriorment, podria revelar un passat alternatiu més obscur que el de «la resta». Això pot implicar la circulació de fets, dades o esdeveniments exagerats o inventats, però també la representació d'un passat imaginat lliure de fets que s'ajusta a l'al-legoria populista de la «verdadera història» de la gent.

Si bé els objectius dels populistes a l'hora d'utilitzar la història falsa són en gran part semblants a aquells que estan darrere de la reavaluació històrica, la història falsa pareix menys probable que el cas anterior per mostrar una dinàmica de dalt a baix. Tot i que els líders polítics la fomenten, aquests han d'actuar amb atenció perquè no se'ls desacredite públicament. Per tant, aquest tipus d'abús de la història es propaga principalment de manera horitzontal en lloc de des de dalt. No cal dir que les xarxes socials són un canal particularment propici per a difondre aquestes mentides (per exemple, amb mems històrics).

La fabricació de parts de la història feixista és un camp prolífic en el discurs polític d'Itàlia. Un tema particularment recurrent, estretament relacionat amb la reavaluació del règim de Mussolini, és l'atribució a aquest últim dels èxits que, en realitat, pertanyen a altres períodes de la història. Una preconcepció comuna és que el règim feixista va establir el primer sistema de pensions en tot el país i el fons de pensions corresponent, l'INPS (Istituto nazionale della previdenza sociale). Aquest fragment d'història falsa (el precursor de l'INPS va ser fundat en 1898) ha adquirit molta popularitat en els últims anys entre els populistes de dreta que s'esforcen per mostrar que fins i tot el criticat règim feixista va ser més compassiu que els tecnòcrates dels governs d'avui dia obsessionats amb la disciplina fiscal. El líder de la Lliga, Matteo Salvini, és un defensor freqüent d'aquesta història falsa (Mollica, 2018): «s'hi van fer moltes coses bones durant el període feixista, per exemple, la introducció del sistema de pensions». Fent ressò de Salvini, Roberta Lombardi (Globalist, 2018) hi va agregar: «quan es tracta del feixisme, hi ha un principi [és a dir, antifeixisme] en la nostra constitució a què m'adherisc totalment. Però si pense en l'INPS, crec que va ser una conquesta per a la civilització».

En comptes d'atribuir els èxits d'una altra persona al règim feixista, una altra branca de la història falsa minimitza $o$, fins $i$ tot, nega els crims, la violència $i$ la destrucció que va provocar la dictadura al país i a l'estranger. En aquesta categoria trobem totes les variacions imaginables sobre el tema d' $\mathrm{d}^{\prime}$ italians bons, alemanys roïns», que atribueix tots els pitjors actes d'Itàlia durant la Segona Guerra Mundial a la «influència malvada» de l'Alemanya nazi (per exemple, Mammone, 2006; Morgan, 2009; Focardi, 2013). Una vegada més, tot i que aquest tipus de narrativa també s'empra més enllà de la dreta de l'espectre polític, són els moviments populistes de dreta els que ho troben especialment útil políticament. Un altre cas d'aquest tipus d'història falsa es mostra en l'afirmació extravagant de Silvio Berlusconi (Hooper, 2003) segons la qual «Mussolini mai no va matar ningú (...) [ell] va enviar persones de vacances», referint-se a la pràctica del règim de confinar els enemics polítics a llocs aïllats, com illes, per neutralitzar-los políticament i tallar els seus vincles amb la resta de la societat.

Finalment, però no menys important, una certa història falsa destaca Itàlia i els italians com a víctimes dels estrangers per suavitzar de manera indirecta les 
crítiques al règim feixista. N'és un exemple la massacre de les foibe, l'assassinat dels italians que vivien a Dalmàcia i Venècia Júlia per part de partisans iugoslaus, un esdeveniment històric que està lluny de ser fals, però en què els populistes de dreta unflen regularment el nombre de víctimes molt per damunt de les dades provades. Curiosament, aquest també és un cas en què les fotos s'han usat descaradament per a provocar l'odi. Per exemple, hi una imatge, ara infame, que mostra un grup de soldats presumptament iugoslaus que es preparen per executar cinc civils desarmats. Això ho fa servir una vegada rere l'altra la dreta - per exemple, l'exministre i president de la regió del Laci, Francesco Storace (Lonigro, 2016) - per a demostrar la crueltat dels comunistes contra els inofensius italians. Els experts han demostrat que la imatge mostra exactament el contrari, és a dir, soldats italians (recognoscibles pels uniformes) a punt d'executar alguns civils eslovens durant l'ocupació feixista d'Eslovènia en la Segona Guerra Mundial.

Als Països Baixos, les experiències del nacionalsocialisme en temps de guerra, l'Holocaust i la col-laboració amb els ocupants nazis, encara es tradueixen en un esquema moral dicotòmic del bé i el mal en el discurs públic i s'eviten els intents de reescriure la història (almenys públicament). Consegüentment, els populistes de dreta eviten generalment els assumptes relacionats amb la Segona Guerra Mundial quan construeixen històries falses. De la mateixa manera que amb la reavaluació d'un passat nacional obscur, l'Holanda colonial i imperial d'antany s'utilitza per a fabricar històries falses o presentar il·lustracions històriques que no corresponen a cap fet. Una cosa clarament relacionada amb la narrativa de disculpa del passat noble de l'imperialisme holandés és que els populistes de dreta han parlat de la victimització holandesa en la història colonial. Encara que la manipulació no és tan clara com en les històries falses, en aquesta estratègia discursiva els populistes de dreta holandesos fan afirmacions històriques molt dubtoses, esguitades de fets suposats que sempre resulta que no tenen un suport empíric clar ni referències transparents. Un trop recurrent és la suposada esclavitud dels holandesos (blancs) per part dels àrabs musulmans.
Després que començara com una referència solta a un article polèmic en el Jewish World Review de l'economista nord-americà Thomas Sowell (2010), l'antiislam va utilitzar la idea que hi va haver més europeus esclavitzats pels musulmans al nord d'Àfrica que africans esclavitzats als Estats Units. A Holanda, Martin Bosma es va fer ressò de l'afirmació de Sowell en el seu llibre provocatiu. L'obra es va escriure com una acusació als cosmopolites «d'esquerra» i els seus interessos inconfessables en la política i la societat holandesa i europea. Bosma argumenta que la comprensió pública del passat nacional holandés tergiversa la història com si es tractara d'una foto retocada amb Photoshop. Argumenta que aquesta versió amaga «segles de domini islàmic» sota els quals els holandesos i altres europeus van ser «sotmesos» (Bosma, 2010). Com que l'afirmació de Sowell va tornar a fer-se viral en 2016, un diari holandés de qualitat va decidir verificar-ho (NRC, 2016). En un primer moment, el $N R C$ va verificar la versió de Sowell. Un any més tard, Thierry Baudet va tornar a tuitar el mateix argument enmig d'una nova polèmica. Aquesta vegada es tractava de la pràctica de pintar-se la cara de color negre per a la festivitat nadalenca de Sinterklaas. Com que aquesta festivitat té fortes connotacions colonialistes i racistes, es va revifar la polèmica anterior després que diversos intel-lectuals i historiadors insistiren en els errors i les falsificacions que el diari havia passat per alt. El $N R C$ va rectificar i va concloure que la tesi de Sowell era falsa i insostenible. No obstant això, Baudet i el seu partit continuaven al-ludint al trop d'«esclaus holandesos» en els mítings. Això és el que l'expert en feixisme i populisme Federico Finchelstein (2019) va denominar l'ús que feien els populistes de la «falsedat deliberada com a arma contra la veritat», pel que fa a la història.

Una altra estratègia discursiva que empren sovint els populistes de dreta, en especial Geert Wilders i el Partit per la Llibertat, és la invocació d'una imatge nacional històricament inexacta. Aquesta falsa imatge és producte d'una vaga iconografia històrica d'una nació autònoma i homogènia. A principis de novembre de 2017, Wilders va pronunciar al parlament (Tweede Kamer, 2017) un discurs apassionat sobre un passat 
holandés imaginari en què es projectaven valors centrals d'autodeterminació, sobirania nacional i homogeneïtat cultural:

El nostre país va ser una vegada el país més bell del món, amb les seues pròpies fronteres, la seua pròpia cultura. Gastàvem els nostres diners en la nostra pròpia gent. Teníem una bona atenció mèdica per als nostres ancians (...) Teníem un país fort, voluntariós i, sobretot, orgullós de si mateix (...) Ningú no va poder doblegar-nos. Érem sobirans. Preníem les nostres pròpies decisions. Posseíem el nostre propi país i les nostres pròpies fronteres (...) Els Països Baixos eren els Països Baixos. I com de diferent (...) és avui. El nostre país està en joc. Els nostres interessos han estat perjudicats. Molts holandesos s'han convertit en estrangers al seu propi país (...) El nostre país, la nostra base d'operacions, el miracle que els nostres avantpassats han construït amb sang, suor i llàgrimes, s'està regalant.

Quan el parlamentari liberal progressista Alexander Pechtold va preguntar a Wilders a quin període es referia realment, Wilders va respondre: «abans de 1850, aproximadament». Aquest tipus de combinació anacrònica de benestar xovinista, sobirania nacional i unitat etnocultural ha servit repetidament, tant de manera visual com discursiva, com un imaginari nacional mític. És un passat nacional «fals» que representa el «cor» històric del poble i forma part del discurs polític de Wilders (Taggart, 2000). Tot i que no està directament relacionat amb la lluita contra un passat nacional obscur, aquest imaginari nacional mític desafia clarament el passat holandés obscur, sostingut empíricament, que s'ha destacat en el discurs intel-lectual i públic. En el seu estudi sobre el Partit per la Llibertat, Koen Vossen (2017: 41) argumenta que aquestes narratives de la suposada historicitat del «poble» s'ajusten a la construcció d'una cultura nacional que és un «fenomen recognoscible i indivisible que es remunta a segles» $i$ hauria de servir com la base de l'«orgull nacional».

\section{EVOCAR I DESPRÉS NEGAR CONNEXIONS AMB EL PASSAT OBSCUR}

Els populistes també usen referències al passat obscur d'una tercera manera més subtil en distanciar-se i negar connexions entre ells i els casos, els períodes i els personatges històrics negatius. Aquest és un últim recurs, per dir-ho d'aquesta manera, que els populistes adopten en aquells aspectes del passat obscur que en general es consideren inacceptables i que és poc probable que es minimitzen o falsifiquen. El racisme en general o l'antisemitisme en particular són exemples d'aquests aspectes.

El que és interessant en aquestes negacions és que sovint apareixen després que els populistes de dreta realment hagen fet o dit quelcom que evoca en la ment de l'audiència la connexió que després es nega. Aquesta resposta no és del tot sorprenent. Les dues parts, insinuació i negació, sovint van de la mà en el que pareix una maniobra perversa per donar gat per llebre, en què el populista mata dos pardals d'un tir: d'una banda, guanya reconeixement a ulls de les seccions extremes de l'electorat per mitjà de l'ús de certes declaracions, símbols o algunes formes més subtils d'evocar una resposta instintiva en l'audiència (Wodak, 2015). D'altra banda, per mitjà de la negació, tranquil-litzen els votants més moderats i els actors polítics pel que fa a les seues credencials democràtiques. Aquest missatge dual, aparentment inconsistent però totalment intencional, és una característica comunicativa establerta dels moviments de dreta, com documenta, per exemple, Cheles (2010) en relació amb el partit postfeixista italià Aliança Nacional.

Com es mostra més amunt, els populistes de dreta italians sovint atrauen una part de la població donant brillantor al passat feixista del país. De vegades, l'atractiu és brutal i no té excuses. No obstant això, estem parlant d'un enfocament més suau que evita parlar sense embuts i, en el seu lloc, es basa en símbols, paraules de moda, gestos i coses semblants. Per exemple, Matteo Salvini mai no es presentaria obertament com un simpatitzant feixista; però el fet que se l'haja fotografiat en companyia dels líders de CasaPound —un moviment social inspirat obertament 
per la ideologia feixista - i vestit amb la roba d'una marca que s'hi vincula alça sospites.

No obstant això, la invocació més recent de Salvini al feixisme es relaciona amb l'ús, per mitjà de les xarxes socials, de diverses paraules de moda i citacions comunament associades amb Il ventennio. En una resposta als crítics en un tuit del 29 de juliol de 2018 (el mateix dia de l'aniversari de Mussolini), Salvini va declarar «tanti nemici, tanto onore» [molts enemics, molt d'honor], que és només una lleugera variació del famós eslògan «molti nemici, molto onore», atribuït al Duce (Il Messaggero, 2018). Dos «incidents» molt semblants, en els quals Salvini va utilitzar frases feixistes i que van ocórrer amb pocs dies de diferència: en un, Salvini va escriure en la seua pàgina de Facebook que «qui es deté està perdut» (Ruccia, 2018). En l'altre, mentre comentava les advertències de la Comissió Europea sobre el pressupost d'Itàlia per a 2019, Salvini va dir amb orgull «No m'importa res!» (Adnkronos, 2018).

El Moviment Cinc Estrelles no és immune a aquestes invocacions. Beppe Grillo, el comediant que va cofundar i continua sent el carismàtic líder d'aquest moviment, va declarar una vegada, en presència d'alguns periodistes, que no tenia res en contra que un membre de CasaPound s'unira al seu moviment; una declaració que molts van veure com un intent d'atraure partidaris d'aquell costat de l'espectre polític (La Stampa, 2013). I si parlem de símbols, moltes vegades Grillo crida «Italiani!» durant els seus espectacles igual que ho feia Mussolini quan es dirigia a les multituds des del balcó del Palazzo Venezia. Un dispositiu còmic efectiu que podria interpretar-se com un intent de fer l'ullet a una certa part de l'electorat, alhora que, per mitjà de la burla, desactiva el tema del feixisme.

L'última observació és important perquè ens porta directament a l'estratègia preferida dels populistes de dreta italians per negar qualsevol vincle o proximitat a l'obscur passat del país. Per exemple, afirmen que el feixisme és cosa del passat $i$, per tant, qualsevol intent de vincular-los a aquesta ideologia no només seria fals sinó que tampoc no tindria sentit. Aquesta estratègia és especialment important per al Moviment Cinc Estrelles, que ha construit gran part de la seua narrativa política sobre la base de transcendir les etiquetes d'esquerra i dreta. Per exemple, quan se li va preguntar sobre l'adhesió oberta de son pare a la ideologia feixista, Alessandro Di Battista (Sannino i Vecchio, 2017), un dels líders del moviment, va respondre que és més important ser honest que antifeixista, i que "parlar sobre feixisme en 2016 és com parlar sobre güelfs i gibel-lins» ${ }^{2}$.

Negar la possibilitat d'un retorn del feixisme amb una disfressa diferent és una manera recurrent de negar connexions enutjoses per part dels populistes d'extrema dreta. Tant Salvini com Giorgia Meloni, la líder de Germans d'Itàlia, un partit de dreta més xicotet, van utilitzar aquest enfocament quan Luca Traini -l'excandidat municipal de la Lliga Nord i simpatitzant nazi- va disparar contra diversos immigrants africans a Macerata en febrer de 2018. La naturalesa racista de l'atac i l'ús de la violència política al país va ser evident. Tot i això, Salvini (Il Fatto Quotidiano, 2018) va comentar que «aquesta idea d'un perill feixista, de la tornada del feixisme, d'una nova onada de camises negres, és surrealista per a mi, i la utilitza una facció política que, en sis anys, ha demostrat que és vàcua». Les paraules de Salvini es van fer ressò de les de Giorgia Meloni (Globalist, 2018):

Els polítics haurien de preocupar-se per aquells terroristes [estrangers] amb seu a Itàlia en comptes de continuar aquest debat surrealista sobre la tornada del feixisme. Allò que va succeir a Macerata és l'acció d'un llunàtic violent, i punt. Si Mein Kampf estava entre les seues lectures, és cosa d'ell. No és la tornada del feixisme.

En les etapes formatives, el Partit per la Llibertat de Geert Wilders, fundat en 2006, es va associar amb símbols utilitzats anteriorment pel moviment nacionalsocialista holandés en les dècades de 1930 i 1940. Quan el partit va presentar el seu logotip en 2008, els historiadors es van afanyar a assenyalar la seua semblança inquietant. La gavina al centre del logotip combinada amb la paraula

2 Faccions polítiques dels segles XII i XIII a la Itàlia medieval. 
llibertat era molt semblant a un cartell de 1941 imprés pel moviment nacionalsocialista holandés i el logotip de la seua lliga juvenil (Historisch Nieuwsblad, 2008). Geert Wilders va respondre amb fúria i va afirmar que no pot «tenir en compte totes les males organitzacions del món que han usat símbols» i que la comparació que s'ha fet entre el seu partit i els nacionalsocialistes només se li pot ocórrer a «una ment malalta» (Trouw, 2008). En altres declaracions es va distanciar de qualsevol inclinació o suport nacionalsocialista argumentant que la gavina va ser idea de la companyia publicitària a què va encarregar el disseny del logotip del partit. A pesar de les similituds òbvies, el PVV va mantenir el logotip sense canvis, encara que en els últims anys ha aparegut amb menys freqüència en la propaganda.

Anys més tard, el Partit per la Llibertat va tornar a lluir un símbol que recordava el repertori visual dels nacionalsocialistes holandesos. En 2011, dos parlamentaris del Partit per la Llibertat van decorar les finestres de les seues oficines parlamentàries amb les anomenades banderes del príncep, una tricolor horitzontal de color taronja, blanc i blau. Aquesta bandera en particular va ser utilitzada ben sovint pels nacionalsocialistes holandesos en les dècades de 1930 i 1940 com a alternativa a la bandera holandesa oficial (roig, blanc, blau), però ha tingut una història molt més llarga. Els primers a hissar-la van ser els orangistes durant la revolta holandesa contra la dominació espanyola (1568-1648) i també va inspirar el govern sud-africà a dissenyar la bandera que es va associar amb el règim de l'apartheid (The Economist, 2015). Durant les últimes dècades, els moviments marginals neonazis i ultranacionalistes holandesos també han adoptat la bandera en la seua iconografia. Com a tal, la bandera té significats múltiples que al-ludeixen a un nexe opac de patriotisme, racisme i col-laboracionisme. No hi va haver resposta oficial de Wilders ni dels dos parlamentaris involucrats, però les banderes es van retirar de les oficines del partit, ja que els periòdics van informar àmpliament sobre les fosques connotacions que tenien.

No obstant això, aquell no va ser el final de la bandera del príncep. Durant una manifestació del Partit per la
Llibertat a l'Haia en setembre de 2013, es van veure entre els assistents diverses versions de la tricolor, la qual cosa mostrava que els partidaris de Wilders l'havien acceptada com a pancarta. Aquella mateixa setmana, quatre parlamentaris del Partit per la Llibertat, entre els quals estava Bosma, van portar un pin de la bandera del príncep a la solapa durant el debat general anual parlamentari (NRC, 2013). El partit de Wilders no va fer cap declaració pública formal, després que hi sorgiren preguntes sobre per què els parlamentaris portaven un pin que tenia vincles clars amb el nacionalsocialisme holandés. En els anys següents, Martin Bosma va continuar lloant la bandera com «el símbol centenari de la nostra llibertat» (Twitter, 2015), i també va fer al·lusió a «una gran unió cultural holandesa» entre els Països Baixos, Flandes i la comunitat afrikaner de Sud-àfrica (Volkskrant, 2014).

Tot i que de forma diferent, trobem un comentari de Thierry Baudet en un esdeveniment en 2017 que també al-ludeix al tema de l'obscur passat holandés de la Segona Guerra Mundial i el feixisme d'entreguerres. Aquest comentari el va reprendre l'extrema dreta radical i els blogs i, en última instància, els mitjans de comunicació principals. Baudet va observar un «odi a allò nacional (...) que intentem transcendir (...) diluint homeopàticament la població holandesa amb tots els pobles del món» (NPO Radio 1, 2017). Inicialment, Baudet va rebutjar totes les acusacions racistes i es va negar a acceptar la reminiscència amb metàfores i eugenèsia de puresa racial anteriors a la guerra. En un programa de televisió nacional, va afirmar que «no volia dir res sobre la raça (...) es tracta de la cultura» $\mathrm{i}$ va agregar que no tornaria a utilitzar aquelles paraules en veure la consternació «desconcertant» que havia creat (Pauw, 2017). No obstant això, se n'han inclòs variacions amb contingut racial i codificades en les proclames de presumpte «odi al nacional» o sobre omvolking (la substitució d'un poble per un altre) o Grand Remplacement (en les paraules del teòric i escriptor francés de la conspiració Renaud Camus). Ambdós termes s'usen per a plasmar una pretesa conspiració elitista que pretenia mesclar holandesos ètnics amb altres «pobles», a què han fet referència tant Wilders com Baudet (Oudenampsen, 2019). 
Aquests exemples mostren com els populistes i nativistes de dreta fan servir trops contaminats d'un passat obscur quan neguen qualsevol connexió amb aquell passat i se'n distancien. No obstant això, també es neguen a acceptar que expressions, metàfores 0 símbols concrets continguen semàntiques amb una relació innegable amb un passat nacional obscur en particular. Es podria argumentar que el raonament complex o historicista sobre el passat s'evita conscientment per projectar un ideal nacional sobre un passat mític o nostàlgic. Els populistes al-leguen que les elits políticament correctes i cosmopolites han enfosquit aquest ideal.

\section{COMPRENDRE LA MOBILITZACIÓ POPULISTA DELS PASSATS NACIONALS}

Els polítics convencionals articulen habitualment un passat noble com a part de la lectura de la història, com un procés del progrés continu i l'avanç cultural, on la història (nacional) condueix cap a una llibertat, prosperitat, igualtat i inclusió cada vegada més grans. Les referències a episodis històrics obscurs ben coneguts també poden formar part d'aquesta narració, en què s'insisteix en la capacitat de recuperació nacional i el talent de la societat per a tornar al noble camí del progrés. L'arribada d'un número considerable de polítics populistes de dreta als parlaments i organismes executius a Europa ha desafiat aquesta estratègia discursiva, retòrica i narrativa de llarga duració en la política dominant. Els populistes han convertit el passat en un camp de batalla. Ara discuteixen i rebutgen les interpretacions generalment acceptades d'episodis històrics vergonyosos i intenten relativitzar-los i tergiversar-los. Explorant aquest nexe entre el populisme i el passat obscur, hem proposat tres estratègies, analíticament distintes, amb què els populistes de dreta avaluen, aborden o al-ludeixen als episodis històrics obscurs de la seua nació: (a) la reavaluació positiva de la història obscura, (b) el recurs a la història falsa i (c) l'evocació i negació posterior de les connexions amb el passat obscur. Les tres estratègies revelen com els populistes de dreta contradiuen les narratives mestres establertes del passat obscur d'una nació.
Com han demostrat els nostres exemples d'Itàlia i els Països Baixos, aquests passats giren entorn de temes i trops recurrents. A Itàlia, deriven de l'etapa feixista de Mussolini; mentre que als Països Baixos el passat colonial, tant modern com imperialista, és el principal - tot i que no l'únic - medi de cultiu per reescriure el passat que utilitzen els populistes de dreta. Independentment de l'estratègia discursiva emprada, els (ab)usos dels passats obscurs estan orientats a la recuperació d'un passat nacional mític o verdader. Aquest passat admirable, segons argumenten els populistes, ha estat diluït per la correcció política hegemònica de les elits. el presenten com un referent crucial perquè la gent lluite contra la migració, la globalització, Europa, les elits corruptes i l'odi al seu propi país. Tots aquests elements, al-leguen, han frustrat el progrés nacional. Siga reavaluant un episodi obscur, inventant fets o imatges històriques, o interactuant amb un passat prohibit, les estratègies emprades sovint culminen en al-lusions directes o indirectes a un passat imaginat en què les virtuts nacionals i l'autodeterminació van de la mà de l'homogeneïtat etnocultural de la gent autòctona del país. En definitiva, es tracta de reclamar la història verdadera de la gent. Com diu l'estudiós del populisme Cas Mudde (2016), les persones «es deixen seduir per un passat públic imaginari que està en línia amb el seu propi passat privat imaginat». Aquest procés pot ser el resultat d'intervencions públiques de dalt a baix (com reavaluar un passat obscur) a mobilitzacions més horitzontals d'inexactituds històriques (com amb la història falsa). Un estudi recent que analitza les raons per les quals els votants holandesos i francesos van optar per Wilders i Le Pen evidencia que aquesta doble dinàmica mostra com els passats fabricats aprofiten els discursos vernacles d'identitat nacional que commouen els partidaris del populisme de dreta (Damhuis, 2018).

Aquest assaig només ha començat a abordar i ordenar la mobilització política de passats obscurs per part de populistes de dreta en el discurs públic i polític. En línia amb una estratègia de comparació del cas més diferent, ha explorat un número limitat d'exemples il-lustratius italians i holandesos en què les estratègies discursives s'apliquen a un pas- 
sat disputat que commou el públic en general. La investigació sobre el populisme de dreta o de dreta radical ha demostrat que aquestes estratègies s'han estés per tot Europa. Altres exemples destacats són el polític austríac d'extrema dreta Jörg Haider, la dinastia francesa Le Pen i el primer ministre hongarés, Viktor Orbán. Per a provar la tipologia preliminar de les estratègies discursives que hem proposat, cal una investigació empírica comparativa i sistemàtica sobre aquests i altres exemples. Creiem que aquestes pautes d'investigació ens ajudaran a comprendre més bé la composició ideològica dels populistes de dreta i la forma en què el passat es mobilitza políticament en els repertoris discursius i retòrics.

\section{REFERÈNCIES BIBLIOGRÀFIQUES}

Adnkronos (2018, setembre 29). Salvini rispolvera 'me ne frego'. Recuperat el 25 d'octubre. Recuperat de 2018 de http:// www.adnkronos.com/fatti/politica/2018/09/29/salvini-rispolvera-frego-precedenti_ejR2Wf9zic9zhT09oZ0LxJ. html.

Albertazzi, D. i McDonnell, D. (ed.). (2008). Twenty-First Century Populism: The Spectre of Western European Democracy. Basingstoke: Palgrave MacMillan.

Bosma, M. (2010). De Schijn-Élite Van De Valse Munters: Drees, Extreem Rechts, De Sixties, Nuttige Idioten, Groep Wilders En Ik. Amsterdam: Bert Bakker.

Bosma, M. (2015, octubre 31). Prachtig. De kleuren van de Prinsenvlag. Eeuwen symbool van onze Vrijheid. Oranje, blanje, blue. @KvanOosterom [Tweet]. Recuperat el 24 d'octubre de 2018. Recuperat de https://twitter.com/ martinbosma_pvv/status/660432306214162436.

Canovan, M. (1981). Populism. Londres: Junction Books.

Canovan, M. (2005). The People. Cambridge: Polity.

Caramani, D. i Manucci, L. (2019). National Past and Populism: The Re-Elaboration of Fascism and Its Impact on Right-Wing Populism in Western Europe. West European Politics, 42(6), 1159-1187.

Cheles, L. (2010). Back to the Future. The Visual Propaganda of Alleanza Nazionale (1994-2009). Journal of Modern Italian Studies, 15(2), 232-311.

Curridori, F. (2018, gener 29). Adinolfi: 'Mussolini fece anche cose buone'. Il Giornale. Recuperat el 20 d'octubre de 2018. Recuperat de http://www.ilgiornale.it/news/politica/adinolfi-mussolini-fece-anche-cose-buone-1488099. html.

De Volkskrant. (2014, maig 21). PVV'er Martin Bosma voorziet ondergang blank Nederland. Recuperat el 24 d'octubre de 2018. Recuperat de https://www.volkskrant.nl/nieuws-achtergrond/pvv-er-martin-bosma-voorzietondergang-blank-nederland b2c8bb93/.

Damhuis, K. (2018). Roads to the Radical Right: Understanding Different Forms of Electoral Support for Radical Right-Wing Parties in France and the Netherlands. PhD dissertation European University Institute.

Davi, K. (2013, març 13). Borghezio (LN): Terzo Reich aveva lati positivi non conosciuti. KlausCondicio. Recuperat el 23 d'octubre de 2018. Recuperat de https://www.youtube.com/watch?v=3S_NJV19uyo.

Eatwell, R. (2017). Populism and Fascism. En C. Rovira Kaltwasser, P. Taggart, P. Ochoa Espejo i P. Ostiguy (ed.), The Oxford Handbook on Populism, 363-83. Oxford: Oxford University Press.

Eatwell, R. i Goodwin, M. (2018). National Populism: The Revolt against Liberal Democracy. Londres: Pelican.

Elsevier. (2018, gener 16). 'Politiek correcte beeldenstorm': jacht op koloniale beelden en namen laait op". Recuperat el 24 d'octubre de 2018. Recuperat de https://www.elsevierweekblad.nl/nederland/achtergrond/2018/01/jachtop-koloniale-beelden-en-namen-laait-weer-op-576734/.

Fieschi, C. (2004). Fascism, Populism and the French Fifth Republic: In the Shadow of Democracy. Manchester: Manchester University Press. 
Finchelstein, F. (2017). From Fascism to Populism in History. Berkeley, CA: University of California Press.

Finchelstein, F. (2018). Fascism and Populism. En C. de la Torre (ed.), Routledge Handbook of Global Populism, 321-32. Londres: Routledge.

Finchelstein, F. (2019, abril 23). Why Far-Right Populists Are at War with History. Washington Post. Recuperat el 27 de setembre de 2019. Recuperat de https:/www.washingtonpost.com/outlook/2019/04/23/why-far-rightpopulists-are-war-with-history/.

Focardi, F. (2013). Il cattivo tedesco e il bravo italiano. La rimozione delle colpe della Seconda guerra mondiale. Bari: Laterza.

Forum. (2017, agost 31). Over vier jaar wil Thierry Baudet aan de formatietafel zitten. Recuperat el 24 d'octubre de 2018. Recuperat de https://www.vno-ncw.nl/forum/over-vier-jaar-wil-thierry-baudet-aan-de-formatietafelzitten.

Furedi, F. (2018). Populism and the European Culture Wars. The Conflict of Values Between Hungary and the EU. Londres: Routledge.

Globalist. (2018a, febrer 12). La 'almirantiana' Roberta Lombardi torna a parlare di fascismo buono". Recuperat el 24 d'octubre de 2019. Recuperat de https://www.globalist.it/politics/2018/02/12/la-almirantiana-roberta-lombarditorna-a-parlare-di-fascismo-buono-2019317.html.

Globalist. (2018b, febrer 4). Giorgia Meloni parla di Macerata e si supera: fascismo e razzismo non esistono. Recuperat el 25 d'octubre de 2018. Recuperat de https://www.globalist.it/politics/2018/02/04/giorgia-meloni-parla-dimacerata-e-si-supera-fascismo-e-razzismo-non-esistono-2018903.html.

Historisch Nieuwsblad. (2008, juny 9). Wilders gebruikt 'besmet' logo. Recuperat el 24 d'octubre de 2018. Recuperat de https://www.historischnieuwsblad.nl/nl/nieuws/10749/Wilders_gebruikt_'besmet'_logo.html.

Hooper, J. (2003, setembre 12). Mussolini Wasn't That Bad, Says Berlusconi. The Guardian. Recuperat el 23 d'octubre de 2018. Recuperat de https://www.theguardian.com/media/2003/sep/12/italy.pressandpublishing.

Il Fatto Quotidiano. (2018, febrer 5). Macerata, Salvini minimizza: 'Nessun allarme fascismo'. Grasso: 'Chi semina odio raccoglie violenza'. Recuperat el 25 d'octubre de 2018. Recuperat de https://www.ilfattoquotidiano.it/2018/02/05/ macerata-salvini-minimizza-nessun-allarme-fascismo-grasso-chi-semina-odio-raccoglie-violenza/4137535/.

Il Messaggero. (2018, juliol 29). "Tanti nemici, tanto onore'. Salvini cita Mussolini ed è bufera politica". Recuperat el 25 d'octubre de 2018. Recuperat de https://www.ilmessaggero.it/primopiano/politica/salvini_mussolini_nemici_ onore-3884636.html.

La Repubblica. (2003, octubre 14). Noi come De Gasperi salvammo la democrazia. Recuperat el 22 d'octubre de 2018. Recuperat de http://www.repubblica.it/2003/j/sezioni/politica/degasperi/degasperi/degasperi.html.

La Stampa. (2013, gener 11). Grillo ai militanti di Casa Pound: 'Se lo volete, benvenuti nei 5 Stelle'. Recuperat el 25 d'octubre de 2018. Recuperat de http://www.lastampa.it/2013/01/11/italia/grillo-ai-militanti-di-casapound-selo-volete-benvenuti-nei-stelle-QOhtlJX18jg5qzKLGqErlN/pagina.html.

La Stampa. (2018, gener 14). 'Nessuno ha fatto più di Mussolini in 20 anni': frase choc dell'esponente Pd fiorentino. Recuperat del 23 d'octubre de 2018. Recuperat de http://www.lastampa.it/2018/01/14/italia/nessuno-ha-fattopi-di-mussolini-in-anni-frase-choc-dellesponente-pd-fiorentino-1a5JFRi518acvTtOpos7TM/pagina.html.

Lonigro, I. (2016, febrer 10). Foibe, Storace su Twitter: "La sinistra dimentica". Ma nella foto sono gli italiani a fucilare gli jugoslavi". Il Fatto Quotidiano. Recuperat el 24 d'octubre de 2018. Recuperat de https://www.ilfattoquotidiano. it/2016/02/10/foibe-storace-su-twitter-la-sinistra-dimentica-ma-nella-foto-sono-gli-italiani-a-fucilare-glijugoslavi/2450842/.

Mammone, A. (2006). A Daily Revision of the Past: Fascism, Anti-Fascism, and Memory in Contemporary Italy. Modern Italy, 11(2): 211-226.

Mammone, A. (2009). The Eternal Return? Faux Populism and Contemporarization of Neo-Fascism across Britain, France and Italy. Journal of Contemporary European Studies, 17(2), 171-192.

McDougall, J. (2016, novembre 16). No, This Isn't the 1930s - But Yes, This is Fascism. The Conversation. Recuperat el 14 de setembre de 2018. Recuperat de https://theconversation.com/no-this-isnt-the-1930s-but-yes-this-isfascism-68867.

Mény, Y. i Surel, Y. (2002). Democracies and the Populist Challenge. Basingstoke: Palgrave.

Moffitt, B. (2016). The Global Rise of Populism: Performance, Political Style, and Representation. Stanford, CA: Stanford University Press. 
Mollica, A. (2018, gener 26). Matteo Salvini ripete la bufala delle pensioni introdotte da Benito Mussolini. Giornalettismo. Recuperat el 24 d'octubre de 2018. Recuperat de https://www.giornalettismo.com/archives/2647201/salvinipensioni-mussolini-bufala.

Morgan, P. (2009). 'I was there, too': Memories of Victimhood in Wartime Italy. Modern Italy 14(2), 217-231.

Mudde, C. (2007). Populist Radical Right Parties in Europe. Cambridge: Cambridge University Press.

Mudde, C. (2016, desembre 15). Can We Stop the Politics of Nostalgia that Have Dominated 2016? Newsweek. Recuperat el 27 de setembre de 2019. Recuperat de https://www.newsweek.com/1950s-1930s-racism-us-europenostalgia-cas-mudde-531546.

Mudde, C. i Rovira Kaltwasser, C. (2017). Populism: A Very Short Introduction. Oxford: Oxford University Press.

Müller, J. W. (2017). What Is Populism? Londres: Penguin.

NPO Radio 1. (2017, març 17). Dit is de dag. Recuperat el 24 d'octubre de 2018. Recuperat de https://www.nporadio1. nl/dit-is-de-dag/onderwerpen/400417-baudet-snapt-ophef-om-homeopatische-verdunning-niet.

NRC. (2013, setembre 26). PVV'ers in Tweede Kamer met omstreden Prinsenvlag. Recuperat el 24 d'octubre de 2018. Recuperat de https://www.nrc.nl/nieuws/2013/09/26/oranje-blanje-bleu-pvvers-in-tweede-kamer-metomstreden-1299388-a1306421.

NRC. (2016, juliol 19). 'Meer Europese slaven in Noord-Afrika dan zwarte slaven in de VS'. Recuperat el 24 d'octubre de 2018. Recuperat de https://www.nrc.nl/nieuws/2016/07/19/meer-europese-slaven-in-noord-afrika-danzwarte-slaven-in-de-vs-3249915-a1512441.

Oudenampsen, M. (2019). De kruistocht van Geert Wilders. De PVV als vertolker van een nieuwe identiteitspolitiek. En G. Voerman i K. Vossen (ed.), Wilder gewogen. 15 jaar reuring in de Nederlandse politiek (105-128). Amsterdam: Boom.

Pauw. (2017, març 10) .@thierrybaudet geeft na geharrewar toe dat zijn opmerking 'homeopatische verdunning van de Nederlandse bevolking' slecht gekozen was" \#penj [Tweet]. Recuperat el 24 d'octubre de 2018. Recuperat de https://twitter.com/pauwnl/status/840332276428750849.

Ruccia, G. (2013, febrer 7). Biancofiore in tv: 'Mussolini? Un grande uomo della storia'”. Il Fatto Quotidiano. Recuperat el 15 de febrer de 2018. Recuperat de https://www.ilfattoquotidiano.it/2013/02/07/biancofiore-shock-in-tvmussolini-grande-uomo-della-storia/220023/.

Ruccia, G. (2018, octubre 10). Salvini cita Mussolini: 'Chi si ferma è perduto'. Gaffe di Alessandra Moretti (Pd): 'È una bellissima frase'. Il Fatto Quotidiano. Recuperat el 25 d'octubre de 2018. Recuperat de https://www. ilfattoquotidiano.it/2018/10/10/salvini-cita-mussolini-chi-si-ferma-e-perduto-gaffe-di-alessandra-moretti-pd-euna-bellissima-frase/4682187/.

Sannino, C. i Vecchio, C. (2017, juny 23). M5s, i due padri fascisti antesignani del 'vaffa': il lessico familiare di Di Maio e Di Battista. La Republica. Recuperat el 25 d'octubre de 2018. Recuperat de https://www.repubblica.it/ politica/2017/06/23/news/m5s_i_due_padri_fascisti_antesignani_del_vaffa_il_lessico_familiare_di_di_maio_e_ di_battista-168863929/.

Sofia, A. (2013, març 5). Roberta Lombardi e il fascismo che spacca il MoVimento 5 Stelle. Giornalettismo. Recuperat el 16 d'octubre de 2018. Recuperat de https://www.giornalettismo.com/archives/809999/roberta-lombardi-e-ilfascismo-che-spacca-il-movimento-5-stelle.

Sowell, T. (2010, abril 27). Filtering History Recuperat el 24 d'octubre de 2018. Recuperat de http://jewishworldreview. com/cols/sowell042710.php3\#.W9gQ-dVKiUk.

Taggart, P. A. (2000). Populism. Buckingham: Open University Press.

The Economist. (2015, juny 23). How an old Dutch flag became a racist symbol. Recuperat el 24 d'octubre de 2018. Recuperat de https://www.economist.com/the-economist-explains/2015/06/22/how-an-old-dutch-flag-becamea-racist-symbol.

Trouw. (2008, juny 10). Wilders woedend over vergelijking met NSB. Recuperat el 24 d'octubre de 2018. Recuperat de https://www.trouw.nl/home/wilders-woedend-over-vergelijking-met-nsb aaba6af2/.

Trouw. (2017, novembre 6). Baudet vult het gat dat God heeft achtergelaten met een geloof in de natie. Recuperat el 24 d'octubre de 2018. Recuperat de https://www.trouw.nl/opinie/baudet-vult-het-gat-dat-god-heeft-achtergelatenmeteen-geloof-in-de-natie a55d9d182/. 
Tweede Kamer. (2017, novembre 1). Meeting 16. Recuperat el 24 d'octubre de 2018. Recuperat de https://zoek. officielebekendmakingen.nl/h-tk-20172018-16-3.html.

Vossen, K. (2017). The Power of Populism Geert Wilders and the Party for Freedom in the Netherlands. Londres: Routledge.

Wodak, R. (2015). The Politics of Fear: What Right-Wing Populist Discourses Mean. Londres: Sage.

\section{NOTA BIOGRÀFICA}

\section{Stefan Couperus}

El Dr. Stefan Couperus és professor de Política i Societat Europea en la University of Groningen als Països Baixos. Va obtindre el seu doctorat en història moderna en la mateixa universitat en 2009 (amb la més alta distinció). Els seus interessos d'investigació inclouen la història de la teoria i la pràctica democràtiques, la història de la governança urbana i la planificació, i els usos del passat en el discurs polític contemporani.

\section{Pier Domenico Tortola}

Pier Domenico Tortola és professor assistent de política i societat europees en la University of Groningen, Països Baixos. Els seus recents interessos d'investigació giren entorn de la política de la crisi de l'Eurozona i les conseqüències d'aquesta última en la governança i les institucions de la Unió Europea. Té un DPhil en política per la University of Oxford. 